\title{
Compression stress in opposite wood of angiosperms: observations in chestnut, mani and poplar
}

\author{
Bruno CLAIR $^{\mathrm{a}, \mathrm{b} *}$, Tancrède ALMERAS ${ }^{\mathrm{c}}$, Junji SugIYAMA $^{\mathrm{a}}$ \\ ${ }^{a}$ Laboratory of Biomass Morphogenesis and Information, Research Institute for Sustainable Humanosphere, Kyoto University, \\ Uji-Kyoto 611-0011, Japan \\ ${ }^{\text {b }}$ Laboratoire de Mécanique et Génie Civil (LMGC), UMR 5508 CNRS, Université Montpellier 2, Place E. Bataillon, CC 48, \\ 34095 Montpellier Cedex 5, France \\ ${ }^{\mathrm{c}}$ Laboratory of Bio-Material Physics, Graduate School of Bioagricultural Sciences, Nagoya University, Nagoya 464-8601, Japan
}

(Received 24 May 2005; accepted 13 December 2005)

\begin{abstract}
In order to face environmental constraints, trees are able to re-orient their axes by controlling the stress level in the newly formed wood layers. Angiosperms and gymnosperms evolved into two distinct mechanisms: the former produce a wood with large tension pre-stress on the upper side of the tilted axis, while the latter produce a wood with large compression pre-stress on the lower side. In both cases, the difference between this stress level and that of the opposite side, in light tension, generates the bending of the axis. However, light values of compression were sometimes measured in the opposite side of angiosperms. By analysing old data on chestnut and mani and new data on poplar, this study shows that these values were not measurement artefacts. This reveals that generating light compression stress in opposite wood contributes to improve the performance of the re-orientation mechanism.
\end{abstract}

reaction wood / compression wood / tension wood / opposite wood / plant biomechanics / growth stresses / microfibrils angle

Résumé - Contraintes de compression dans le bois opposé des angiospermes : observation chez le châtaignier, le manil et le peuplier. Pour s'adapter à l'environnement, les arbres sont capables de contrôler l'état de contraintes des nouvelles couches de bois formé pour réorienter leurs axes. Angiospermes et gymnospermes ont évolué vers deux stratégies différentes : les premiers produisent un bois à forte précontrainte de tension sur la face supérieure de l'axe incliné alors que les derniers mettent en place un bois en précontrainte de compression sur la face inférieure. La différence de contrainte avec la face opposée constituée de bois en légère tension produit un même résultat, la flexion de l'axe. Pourtant, au hasard des expérimentations, des valeurs de compression ont plusieurs fois été observées dans le bois opposé des angiospermes. Cette étude reprend des donnés anciennes sur le châtaignier et le manil et les complète avec des données sur peuplier pour mettre en évidence qu'il ne s'agit par d'erreurs de mesure mais réellement d'une stratégie de ces arbres consistant à produire du bois en légère précontrainte de compression pour une meilleure efficacité du redressement.

bois de réaction / bois de compression / bois de tension / bois opposé / biomécanique végétale / contraintes de croissances / angle des microfibrilles

\section{INTRODUCTION}

During their development, trees are submitted to various mechanical constraints that may cause a permanent change in the orientation of their stem and branches. These constraints are environmental, such as soil instability or damage due to the action of wind or snow, as well as biological, such as the weight of epiphytes or the weight of the stem and crown of the tree itself. Controlling and correcting the orientation of woody axes is then necessary for a tree to adapt to its environment, ensure its long-term mechanical stability and maximise its chances to survive and reproduce.

This morphological plasticity is achieved through the production of reaction wood on one side of the stem [23]. Reaction wood is characterised by a high magnitude of the longitudinal stress generated within wood cells walls during matura-

\footnotetext{
*Corresponding author: clair@lmgc.univ-montp2.fr
}

tion. The asymmetric distribution of maturation stress within the newly formed layers of a stem cross-section creates a bending moment resulting in a change in stem curvature $[2,3,15]$. Gymnosperm and angiosperm species have specific mechanisms for generating this bending moment. Gymnosperms produce compression wood in the lower side of the tilted stem and angiosperms produce tension wood in the upper side $[3,5,14,15,20,25,27]$. In both cases the opposite side is characterised by a "normal" stress, i.e. a light tension.

Because of the stiffness of the internal wood layers, most of the maturation stress in the outer layers of the tree is not released in situ [3]. This can be evidenced and quantified by releasing the longitudinal stress at the surface of wood and measuring the resulting strain, referred to as residual growth strain (RGS). Typical RGS values range from $-0.1 \%$ to $-0.4 \%$ for tension wood (TW), from $-0.015 \%$ to $-0.1 \%$ for normal wood (NW) and from $+0.05 \%$ to $+0.3 \%$ for compression wood (CW) [15]. 
Positive RGS values were sometimes measured in angiosperm opposite wood $[10,11]$. These values were believed to be measurement artefacts. Indeed, metrological studies showed that the methods for measuring RGS may have a non-negligible incertitude $[15,30]$. Also, other sources of mechanical stress are a possible cause of error for the estimation of maturation stress. Any increment of load or change in stem orientation generates an additional stress field inside the tree, referred to as support stress. Growth stress is the sum of maturation stress and support stress. It can be shown that the support stress is low in peripheral wood layers, and generally much lower than maturation stress of reaction wood [3]. However, in certain conditions, it may not be negligible so that the measurement of RGS, even if accurate, is a biased estimation of the maturation strain. This bias may not be negligible when compared to the magnitude of RGS in normal wood.

Recently, performing research on tension wood of species well known to produce high tension stress, some positive RGS values were measured on the opposite side (lower side) of the tilted trees $[10,11]$. In this paper, by considering other physical and micro-structural features usually correlated to the RGS value, we aim at verifying if these measurements were artefacts or if angiosperms develop compression maturation stress in opposite wood to improve the biomechanical performance.

\section{MATERIALS AND METHODS}

Studies were performed on tilted trees of chestnut (Castanea sativa Mill.), mani (Symphonia globulifera L.f.) and poplar (Populus euramericana Guinier). Diameters at breast height were respectively $15 \mathrm{~cm}, 20 \mathrm{~cm}$ and $25 \mathrm{~cm}$. Chestnuts were growing in a private forest in south of France, mani in a tropical rainforest in French Guyana (South America) and poplar in Kyoto university experimental forest (Japan). Experiments on mani and chestnut involved measurements of RGS and longitudinal drying shrinkage, and were presented in details in previous papers $[10,11]$. New data on poplar are also shown, including measurements of RGS and micro-fibril angle.

\subsection{Residual growth strain (RGS)}

Various methods are available for measuring RGS. They are based on the same principle, which consists in measuring the longitudinal strain at the wood surface, after artificially releasing the stress $[15,30]$. For chestnuts and mani, the "single hole" method was used $[11,15]$. With this method, a displacement is measured (in m) and converted into a strain (in \%) using a calibration factor. Empirical and theoretical calibration factors were provided by Fournier et al. [15]. We used the factor $12.3 \times 10^{-4}$ corresponding to a standard hardwood. For poplar experiments, RGS was directly obtained using the strain gauge method described by Yoshida and Okuyama [30].

In the three species, RGS were measured at various positions around the circumference. For each RGS measurement, several measurements of the other feature were performed, at various locations close to the point where RGS were measured.

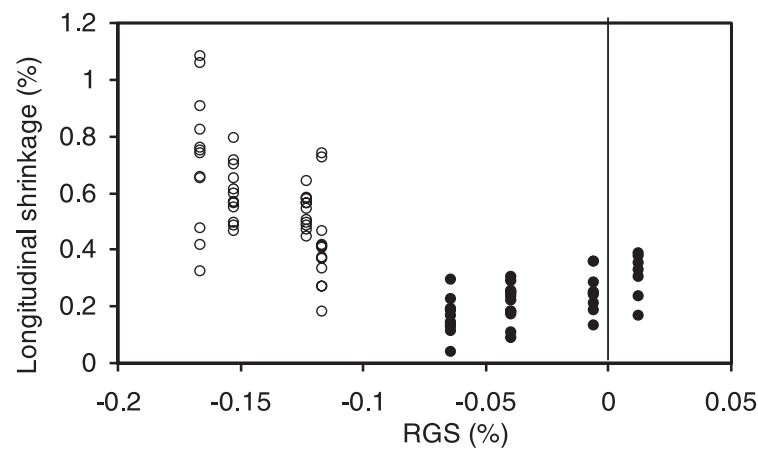

Figure 1. Longitudinal shrinkage measured on chestnut samples versus the residual growth strain. Full circle: normal and "compression" wood. Empty circle: tension wood (modified from [11]).

\subsection{Longitudinal shrinkage}

The length of chestnuts sample $\left(\mathrm{R} \times \mathrm{T} \times \mathrm{L}=1 \times 5 \times 50 \mathrm{~mm}^{3}\right)$ and the thickness of a mani disk $(\mathrm{L}=50 \mathrm{~mm})$ were measured in green and oven-dried condition with a Mitutoyo transducer. Shrinkage was calculated as the dimensional variation between green and dry states, divided by the dimension in the green state $[10,11]$.

\subsection{Microfibrils angle (MFA)}

MFAs were measured in green conditions. A plain sawn plate $\left(\mathrm{R} \times \mathrm{T} \times \mathrm{L}=2 \times 0.5 \times 20 \mathrm{~mm}^{3}\right)$ was mounted in a fibre goniometer, keeping $\theta-2 \theta$ to satisfy the Bragg condition of (004) meridional planes. The intensity distribution was then recorded by rotating the sample with a speed of $6^{\circ} / \mathrm{min}$. The $\operatorname{CuK}(\lambda=0.1542 \mathrm{~nm})$ were generated by X-ray generator (RIGAKU Ultra18HF) operated at $30 \mathrm{kV}$, $300 \mathrm{~mA}$. Parameter T defined by Cave [7] was graphically derived from the diffraction intensity diagrams. The average MFA of each sample was estimated using Cave's formula: $\mathrm{MFA}=0.6 \times \mathrm{T}$. As stated by Cave [8], the intensity diagram obtained from the (004) plane is identical to that obtained from the (200) plane, but suffers contamination from other weak crystalline planes having a similar Bragg angles. Considering that this contamination is low, parameter $\mathrm{T}$ gives useful estimations of the MFA. Also, application of Cave's formula for wood samples having a MFA lower than $20^{\circ}$ is subject to discussion. Values obtained using the "improved Cave's method" [28] were also computed to check the consistency of the results.

\section{RESULTS AND DISCUSSION}

Figures 1 and 2 show the longitudinal shrinkage measured on chestnut and mani versus the RGS. Results on tension wood are presented in order to show the ability of these trees to produce high tensile stressed wood, having a high longitudinal shrinkage, as it is well known $[9,13,17,22]$. Observation of the measured longitudinal shrinkage versus RGS shows a continuum in behaviour from the "normally" tensile stressed wood to the compression stressed wood. Inside the group of normal wood samples (including compression values), RGS and longitudinal shrinkage are significantly correlated $(R=0.60$, 


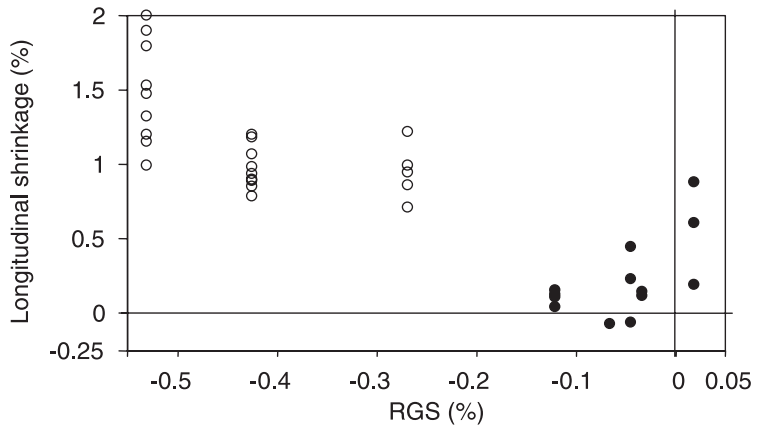

Figure 2. Longitudinal shrinkage measured on mani disks versus the approximate residual growth strain. Full circle: normal and "compression" wood. Empty circle: tension wood.

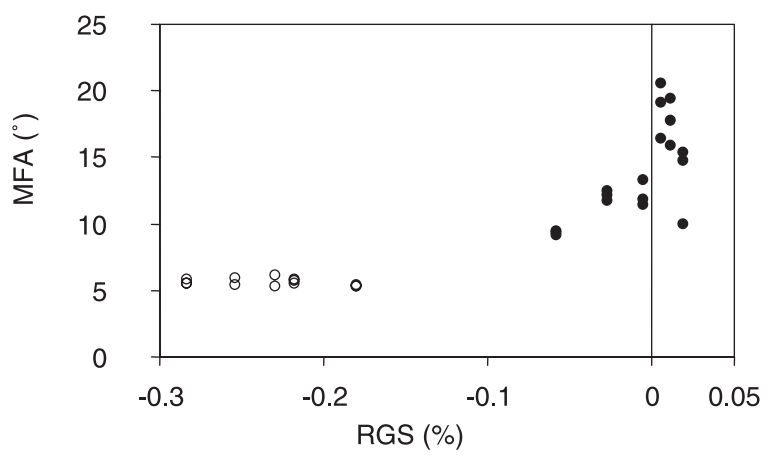

Figure 3. Microfibrils angle estimated on poplar samples versus the residual growth strain. Full circle: normal and "compression" wood. Empty circle: tension wood.

$p<0.001$ for chestnut, $R=0.59, p<0.05$ for mani). Moreover, the mean longitudinal shrinkage of samples with positive RGS is significantly higher than that of normal wood samples having negative RGS (Mann-Whitney U test, $p<0.01$ for chestnut, $p<0.05$ for mani). This tendency is similar to that observed in gymnosperms in the transition between normal and compression wood [24,26].

Figure 3 shows the relation between MFA estimation and RGS for poplar. Results obtained on tension wood are presented in order to confirm the capacity of this tree to generate high tension stresses associated with a very low $\mathrm{MFA}^{1}$, as typically found in gelatinous fibres [16]. For samples with RGS higher than $-0.1 \%$, there is a general trend for the MFA to increase with the RGS. Inside the group or normal wood samples (including compression values), RGS and MFA are significantly correlated $(R=0.67, p<0.005)$. The mean MFA of samples with positive RGS is significantly higher than that of normal wood samples having negative RGS (Mann-Whitney U test, $p<0.001)$. Again, this tendency is typical of the relation

\footnotetext{
${ }^{1}$ Values around $5^{\circ}$ found for tension wood MFA should not be considered as a correct estimate, since the Cave's method [7] used to derive the MFA from the diffraction diagram is not adapted to such low values. Using Yamamoto's improved method [28], negative values ranging between $-1^{\circ}$ and $-5^{\circ}$ were obtained. The real mean value of MFA in tension wood is probably close to $0^{\circ}$.
}

observed in gymnosperms from normal wood to compression wood $[18,26]$.

On the three angiosperms species studied, positive values of RGS between $+0.01 \%$ and $+0.02 \%$ were found. Each time, the values of other features positively correlated to the RGS were found consistently higher in samples with positive RGS. This clearly confirms that the observed positive RGS are not due to measurement errors, but really correspond to a compressive maturation stress.

In the case of poplar, our measurements show that wood with compression maturation stress have higher MFA than typical normal wood. Unfortunately, the MFA of chestnut and mani samples were not measured. However, several experimental and theoretical works showed that the increase in longitudinal shrinkage from normal to compression wood is due to the increase of the MFA $[18,26]$, so that it is likely that a similar observation would have been done on these species. Several works showed that development of compressive maturation stress is a direct mechanical consequence of this large MFA [1, 6, 29].

Even if the RGS value of this wood is lower than that of typical CW of gymnosperms, similar features were observed, concerning the cell structure (MFA), the physical behaviour (shrinkage) and the biomechanical behaviour (RGS). For all features, this opposite wood of angiosperm seems to be an intermediate form between normal wood and typical compression wood, maybe similar to what was observed in gymnosperms in the transition zone between these two tissues [31].

The presence of $\mathrm{CW}$ in angiosperms was previously reported, to our knowledge, only for the case of Buxus (microphylla and sempervirens) $[4,20,32]$ and other primitive angiosperms such as Pseudowintera colorata (Winteraceae) [19]. In the case of these species, the magnitude of RGS, anatomical observations and/or chemical analyses showed that typical $\mathrm{CW}$ was produced close to $\mathrm{CW}$ of gymnosperms $[4,19,32]$. This particular case clearly differs from the results of our study from a biomechanical point of view. Indeed, the biomechanical mechanism of Buxus and Pseudowintera is completely similar to that of gymnosperms, producing $\mathrm{CW}$ with stem eccentricity in the lower side associated and NW in the opposite side.

Trees studied in this paper seem to cumulate advantages of angiosperms and gymnosperms by combining the production of strong TW on one side and a kind of light CW on the opposite side.

Values of RGS in tension wood measured for many species suggest that there may be an upper limit in the tensile stress that can be generated in wood cell walls $[12,21]$. In this case, the biomechanical performance of the re-orientation process can only be improved through complementary mechanisms. Difference in stiffness between NW and TW or stem eccentric growth are known examples of such complementary mechanisms [2]. The simultaneous production of TW on the upper side and $\mathrm{CW}$ in the lower side is an additional mechanism, which allows a substantial improvement of the biomechanical performance. Indeed, the change in curvature induced by reaction wood production is roughly proportional to the difference in RGS between the two sides. For our samples, this 
difference was increased by $17 \%$ to $38 \%$ because light compression wood was produced on the opposite side instead of typical normal wood.

\section{CONCLUSION}

On these three angiosperms species, light compression wood was found in the opposite side of tension wood. Some more investigation, especially on the chemical composition and the anatomical structure, would be interesting to show whether this angiosperm compression wood differs or not from gymnosperm compression wood. In these trees, the reorientation was produced by the cumulative effect of a high tension stress in the upper side of the tilted stem and a low compression stress in the lower side. Combining these two reactions seems to be the best way for improving the biomechanical reactivity of the tree.

Acknowledgements: Authors thank Pr. Tanaka for his kindness in the use of X-ray machine and G. Jaouen for shrinkage measurements on mani. Experiments on mani were performed in the laboratory "Écologie des Forêts de Guyane" (UMR CIRAD - ENGREF INRA 745-CNRS 2728) in Kourou (French Guyana) under the supervision of Pr. Meriem Fournier. The study was supported by the Ademe and the French Ministry of Agriculture in the framework of a project on "Physical and mechanical properties of reaction woods" (convention 61.45.47/00) and by a Grant in Aid for Scientific Research from the Japanese Society of Promotion of Science (Nos. 14656069, 14360099, 14002805). First and second authors received post-doctoral fellowship from Japanese Society for Promotion of Sciences (JSPS).

\section{REFERENCES}

[1] Alméras T., Gril J., Yamamoto H., Modelling anisotropic strains in wood in relation to fibre boundary conditions, microstructure and maturation kinetics, Holzforschung 59 (2005) 347-353.

[2] Alméras T., Thibaut A., Gril J., Effect of circumferential heterogeneity of wood maturation strain, modulus of elasticity and radial growth on the regulation of stem orientation in trees, Trees 19 (2005) 457-467.

[3] Archer R.R., Growth stresses and strains in trees, Springer-Verlag, Berlin Heidelberg New-York, 1986.

[4] Baillères H., Castan M., Monties B., Pollet B., Lapierre C., Lignin structure in Buxus sempervirens reaction wood, Phytochemistry 44 (1997) 35-39.

[5] Barnett J.R., Jeronimidis G., Reaction wood, in: Barnett J.R., Jeronimidis G., Roberts A., Usherwood P.N.R. (Eds.), Wood quality and its biological basis, Blackwell Publishing, Oxford 2003, pp. 118-136.

[6] Boyd J.D., Tree growth stresses - Part V: Evidence of an origin in differentiation and lignification, Wood Sci. Technol. 6 (1972) 251262.

[7] Cave I.D., Theory of X-ray measurement of microfibril angle in wood, For. Prod. J. 16 (1966) 37-42

[8] Cave I.D., Theory of X-ray measurement of microfibril angle in wood, Part 2: the diffraction diagram, Wood Sci. Technol. 31 (1997) 225-234.

[9] Chow K.Y., A comparative study of the structure and composition of tension wood in beech (Fagus sylvatica L.), Forestry 20 (1946) $62-77$.

[10] Clair B., Jaouen G., Beauchêne J., Fournier M., Mapping radial, tangential and longitudinal shrinkages and its relation to tension wood in discs of the tropical tree Symphonia globulifera, Holzforschung 57 (2003) 665-671.
[11] Clair B., Ruelle J., Thibaut B., Relationship between growth stresses, mechano-physical properties and proportion of fibre with gelatinous layer in chestnut (Castanea sativa Mill.), Holzforschung 57 (2003) 189-195.

[12] Clair B., Ruelle J., Beauchêne J., Prevost M.F., Fournier M., Tension wood and opposite wood in 21 tropical rain forest species. 1. About the presence of G layer, IAWA J. 27 (2006) (in press).

[13] Clarke S.H., The distribution, structure and properties of tension wood in beech (Fagus sylvatica L.), J. For. 11 (1937) 85-91.

[14] Coutand C., Jeronimidis G., Chanson B., Loup C., Comparison of mechanical properties of tension and normal wood in Populus, Wood Sci. Technol. 38 (2004) 11-24.

[15] Fournier M., Chanson B., Thibaut B., Guitard D., Mesure des déformations résiduelles de croissance à la surface des arbres, en relation avec leur morphologie. Observation sur différentes espèces, Ann. Sci. For. 51 (1994) 249-266.

[16] Fujita M., Saiki H., Harada H., Electron microscopy of microtubules and cellulose microfibrils in secondary wall formation of poplar tension wood fibers, Mokuzai Gakkaishi 20 (1974) 147-156.

[17] Jourez B., Riboux A., Leclercq A., Comparison of basic density and longitudinal shrinkage in tension wood and opposite wood in young stems of Populus euramericana cv. Ghoy when subjected to a gravitational stimulus, Can. J. For. Res. 31 (2001) 1676-1683.

[18] Meylan B.A., The Influence of microfibril angle on the longitudinal shrinkage-moisture content relationship, Wood Sci. Technol. 6 (1972) 293-301.

[19] Meylan B.A., Reaction wood in Pseudowintera colorata - A vesselless dicotyledon, Wood Sci. Technol. 15 (1981) 81-92.

[20] Onaka F., Studies on compression and tension wood, Wood Res. 1 (1949) 1-88.

[21] Ruelle J., Clair B., Beauchêne J., Prevost M.F., Fournier M. Tension wood and opposite wood in 21 tropical rain Forest species. 2. Comparison of some anatomical criteria, IAWA J. 27 (2006) (in press).

[22] Sassus F., Déformations de maturation et propriétés du bois de tension chez le hêtre et le peuplier : mesures et modèles, Ph.D. thesis, Engref, Montpellier, 1998.

[23] Sinnott E.W., Reaction wood and regulation of tree form, Am. J. Bot. 39 (1952) 69-78.

[24] Skaar C., Wood-water relations, Springer Verlag, Berlin, Heidelberg, New York, 1988.

[25] Thibaut B., Gril J., Growth stresses, in: Barnett J.R., Jeronimidis G.J., Roberts A., Usherwood P.N.R. (Eds.), Wood quality and its biological basis, Blackwell Publishing, Oxford 2003, pp. 137-156.

[26] Timell T.E., Compression wood in Gymnosperms, Vol. 1: Bibliography, historical background, determination, structure, chemistry, topochemistry, physical properties, origin, and formation of compression wood, Springer Verlag, Berlin, Heidelberg, New York, 1986

[27] Wilson B.F., Archer R.R., Tree design: some biological solutions to mechanical problems, Bioscience 9 (1979) 293-298.

[28] Yamamoto H., Okuyama T., Yoshida M., Method for determining the mean microfibril angle of wood over a wide range by the improved Cave's method, Mokuzai Gakkaishi (1993) 375-381.

[29] Yamamoto H., Generation mechanism of growth stresses in wood cell walls: roles of lignin deposition and cellulose microfibril during cell wall maturation, Wood Sci. Technol. 32 (1998) 171-182.

[30] Yoshida M., Okuyama T., Techniques for measuring growth stress on the xylem surface using strain and dial gauges, Holzforschung 56 (2002) 461-467.

[31] Yoshizawa N., Idei T., Some structural and evolutionnary aspects of compression wood tracheids, Wood Fiber Sci. 19 (1987) 343-352.

[32] Yoshizawa N., Satoh M., Yokota S., Idei T., Formation and structure of reaction wood in Buxus microphylla var. insulari Nakai, Wood Sci. Technol. 27 (1993) 1-10. 